Indexed by

\title{
PERFORMANCE IMPROVEMENT ON MOTOR BLDC SPEED CONTROLLER BY USING MULTI CONTROLLER WITH SUMMATION TECHNIQUE
}

Crossref

\section{Widjonarko}

Universitas Jember, Engineering Faculty, Electrical Engineering Department, Jember, Indonesia

KOBSON

\section{Bayu Rudiyanto}

Politeknik Negeri Jember, Renewable Energy Engineering, Engineering Departement, Jember, Indonesia

\section{Cries Avian}

Politeknik Negeri Jember, Renewable Energy Engineering, Engineering Departement, Jember, Indonesia, National Taiwan University of Science and Technology, Electronic and Computer Engineering, Taipei, Taiwan

\author{
Setya Widyawan Prakosa \\ Universitas Jember, \\ Engineering Faculty, Electrical \\ Engineering Department, \\ Jember, Indonesia, National \\ Taiwan Uni-ersity of Science \\ and Technology, Electronic and \\ Computer Engineering, Taipei, \\ Taiwan
}

Key words: ANN, BLDC motor, fuzzy, PID, summation speed controller doi:10.5937/jaes0-30440

Cite article:

Widjonarko., Avian C., Prakosa Widyawan S., Rudiyanto B. (2021) PERFORMANCE IMPROVEMENT ON MOTOR BLDC SPEED CONTROLLER BY USING MULTI CONTROLLER WITH SUMMATION TECHNIQUE, Journal of Applied Engineering Science, 19(4), 902 - 909, DOI:10.5937/ jaes0-30440

Online aceess of full paper is available at: www.engineeringscience.rs/browse-issues 


\title{
PERFORMANCE IMPROVEMENT ON MOTOR BLDC SPEED CONTROLLER BY USING MULTI CONTROLLER WITH SUMMATION TECHNIQUE
}

\author{
Widjonarko $^{1 *}$, Cries Avian², 3 , Setya Widyawan Prakosa1, 3 , Bayu Rudiyanto² \\ ${ }^{1}$ Universitas Jember, Engineering Faculty, Electrical Engineering Department, Jember, Indonesia \\ ${ }^{2}$ Politeknik Negeri Jember, Renewable Energy Engineering, Engineering Departement, Jember, Indonesia \\ ${ }^{3}$ National Taiwan University of Science and Technology, Electronic and Computer Engineering, Taipei, \\ Taiwan
}

BLDC motor is the most widely used in the industrial world, especially in electric vehicles. With this increasing demand, a variety of research topics emerged in BLDC motors. One popular research is on BLDC motor speed control topics to maintain speed for its application, such as intelligent cruise technology in electric cars and conveyors for line assembly. However, from several existing studies, the BLDC Motor controller still uses a single controller model. The controller's output is purely from the controller without any improvement in characteristics and has a problem with the oscillating speed setpoint (error problem). In this study, the researcher proposed a combining control with the concept of summation output to handle this problem. With this concept, the control techniques used can improve each other so that better control can be produced following the control system assessment parameters. The authors used a Fuzzy Logic Controller, Artificial Neural Network (ANN), and PID, which were combined and obtained seven control systems. The results show that the control system can improve several parameters using the summation concept from the seven controllers model. It has a positive overall correlation when viewed in terms of the difference between the Error and the setpoint or MAE (Mean Absolute Error) as parameter assessment.

Key ANN, BLDC motor, fuzzy, PID, summation speed controller

\section{INTRODUCTION}

BLDC motors are one of the most popular motors in the industrial world. One of them is its application to industrial machines, especially electric vehicles [1]. The reasons given vary. Some of them are BLDC motors with better performance than ordinary DC motors, high torque, high efficiency, more comfortable control, increased responsiveness, and ease to repair [2].

If viewed from research developments of BLDC motors, many topics can be found. The first studies related to constructing a BLDC motor [3, 4]. The second is related to the controller's construction used [5]. The third is related to how BLDC motors are combined with renewable energy sources $[6,7]$. The last one is how the BLDC motor speed controller with various applied techniques [8, 9]. This previous research topic is the most exciting. The speed control problem is fascinating because the average BLDC motor is used to maintain speed at a particular setpoint, such as intelligent cruise applications on electric cars [10] and conveyor [11] systems in the industry.

Several studies related to the topic discussed a method to control BLDC motors speed and found in several published articles. Some of these are controlling the BLDC motor using PI [2, 12], PID control [13, 14], Fuzzy Logic Controller [13, 15, 16], and Artificial Neural Network $[17,18]$. For example, Ramesh et al. [35] and Krishna et al. [19] research use Fuzzy Logic Control and PI, and Avian et al. [14] using an Artificial Neural Network as a
BLDC motor controller. These control uses to control BLDC Motor using voltage regulating or any strategies, so the speed of the BLDC Motor can follow the setpoint. Besides research on BLDC motor control applied using single control (independently), several studies use BLDC motor control in pairs or combined with the other controllers in one control circuit. Some of these studies are research conducted by Varshney et al.[20], Anshory et al. [2] and the others [20-23]. In this study, the BLDC motor controller is constructed by a controller combination of Fuzzy and PID. Fuzzy in this system functions to respond to system input values in the way of errors and delta errors. This study's fuzzy output is not the output value that is directly fed to the control system. But the output of the Fuzzy production is the value of $\mathrm{Kp}, \mathrm{Ki}$, and $\mathrm{Kd}$, which will then be provided to the final controller in the form of PID. With this concept, a controller combination in Fuzzy-PID and the PID is created as the final control, directly connected with the BLDC motor speed driver. It also happens in a study conducted by Gobinath et al. [18]. In this study, the researcher combined the Deep Learning Neural Network - Fuzzy - Tuned to control the speed of BLDC Motor by gaining the value of the PID controller, which directly controls the motor inverter. Also research that had been conduted by Ghany et al. [24] uses single neuron PID as control with Fuzzy as it weights tuning. And also Ramya et al. [25] use Fuzzy as main control and ANN for membership function tuning. 
Several existing studies indicate that so far, the combined controller is still controlled using the series concept. This means that the first controller will be in charge of processing input, and the output of the first controller will be fed to the second controller as input. The second controller then processes the input and issues a final value (such as PWM), directly connecting with the motor driver. But unfortunately, if it is observed from several published studies, it can be seen that each controller has its characteristics. Either in the realm of strength or weakness. And then the others problem arising when the series control is used, it could hard to build the system because each series controller must be tuned before it can work together. Without that steps, it might make a system getting worse, causing an asynchronous controller. From this fact, rather than tuning each control supposed to make it synchronous and might take a long time, it certainly opens the opportunity to create a control system, a combination control system without any tuning or synchronization. The combined control system is not a control system that works in series like existing research. However, the proposed control system is a control system that works in parallel, which conceptually can correct each other's controls to get a better control system than if it works alone or in series control.

Therefore, in this study, the researcher will propose a concept of the parallel combined control system. In this study, researchers will research by combining several popular control systems that exist in previous studies. Among them are Fuzzy Controller, Artificial Neural Network (ANN), and PID. This control system's merger process will use the "SUM" function as a gate function whose work is to carry out the compensation process for each combined model. By doing this combination, it is expected that improvements will occur compared to when the controller system works alone. Therefore, to realize and prove the intended contribution of progress, the researcher will compare the controllers, as mentioned earlier, with their combinations in this study. Comparing those models is to assess characteristics of the combined model into parallel (combination) controller to the BLDC speed response. Thus, the controller number should be seven controllers (three single controllers and four combination controllers). Suppose to know the best characteristics of the controller, that controller will be evaluated by using the contribution equation. This equation is an equation to know the contribution of the evaluated controller (between single control and combinational or parallel controller) according to improvement in each parameter assessment. So, contribution parameters will be assessed using statistical parameters that are widely used for control system evaluation, namely ISE, IAE, ITAE, and MAE [26, 27], that determined the stabilizing of the system proposed. By analyzing these parameters, numerically, the system performance can be sensed and measured how much influence the combination control has on the control system that works as a single controller.

\section{SIMULATION SETUP}

\section{Schematic in Simulink}

In this research, the system will be simulated using Simulink Matlab. In the established system, the author uses five essential blocks. The first is the controller block. This block's function is to respond to every change input, then produce a PWM value as output to control the Buck-Boost Converter. The second block is the BuckBoost Converter block, which functions as a control for the voltage that enters the BLDC Motor Controller. The next block is the BLDC Motor Controller, which acts as a BLDC motor speed controller, where the source of this block comes from the Buck-Boost Controller. Therefore the incoming voltage will be directly proportional to the speed produced by the BLDC motor. The fourth block is the BLDC Motor. The fifth block is an encoder block (gate and decoder), which functions to convert the hall sensor signal into a gate signal to power the BLDC motor so that the representation of the system can be seen in Fig. 1.

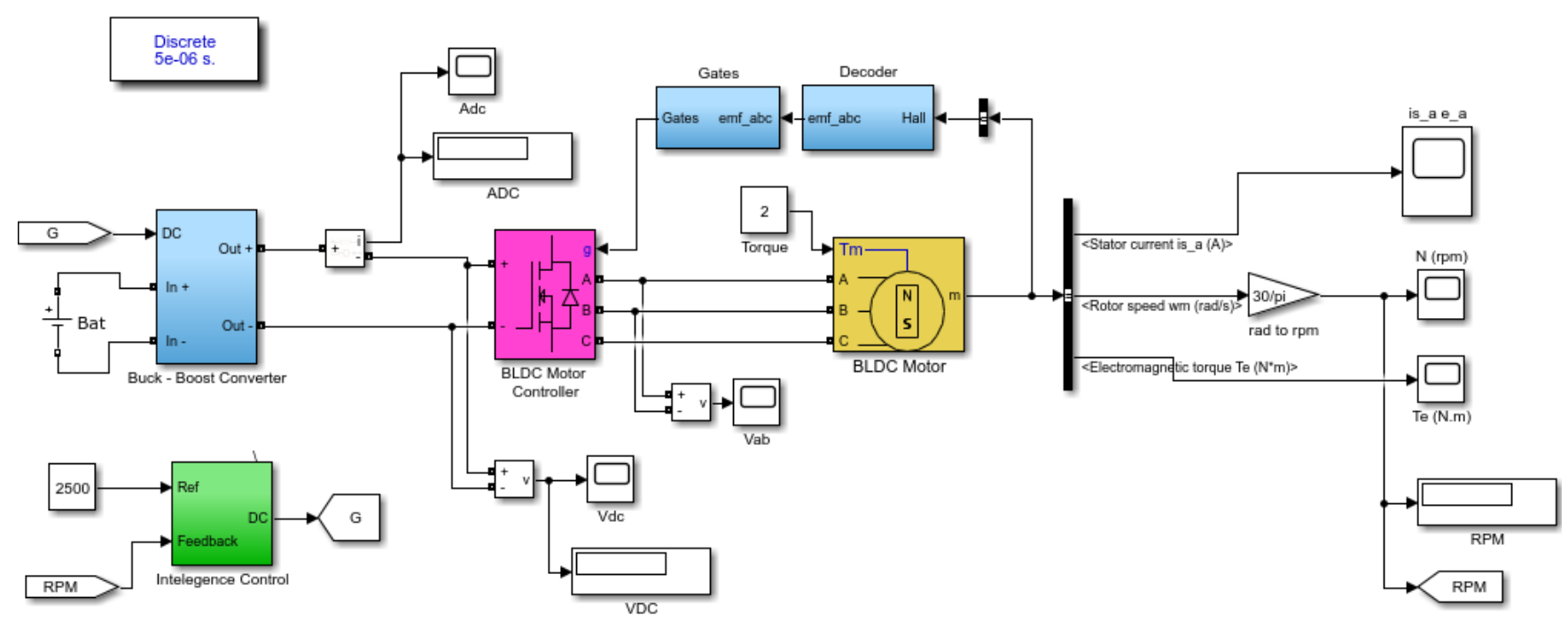

Figure 1: System Setup in Simulink Matlab 


\section{BLDC Motor}

The BLDC motor used is the Permanent Magnet Synchronous Machine (PMSM). The specifications of this motor are by using voltage constant $24 \mathrm{Vrms} / \mathrm{krpm}$ with torque constant $0.324114 \mathrm{~N} . \mathrm{m} /$ Apeak. For stator phase resistance Rs, the value is $0.18 \Omega$, stator phase inductance is $0.000835 \mathrm{H}$. For the inertia is 0.000621417 $\mathrm{Kg} . \mathrm{m}^{2}$, friction factor is 0.000303448 N.m.s, viscous damping $4.5 \mathrm{oz}$.in $/ \mathrm{krpm}$, and pole pairs is 4 .

\section{Buck-Boost Converter}

Meanwhile, the Buck-Boost Converter (BBC) schematic and specifications used to have a schematic, as shown in Fig. 2. At the same time, the parameter and the components used for BBC are voltage source is $200 \mathrm{v}$, inductor (L1) is 200 uh, capacitor (C1) is 103 uh, resistor (R1) is $20 \Omega$, and the frequency that used for PWM is $25000 \mathrm{hz}$.

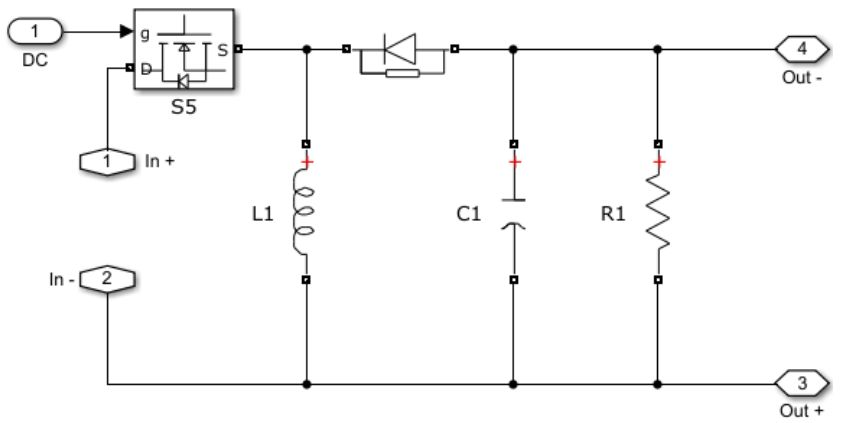

Figure 2: Buck-Boost Converter Schematic

\section{SIMULATION SETUP}

The controllers used in this study consist of three types of controllers. Among these controllers are the Fuzzy Logic Controller, Artificial Neural Network (ANN), and PID. For these controllers' design, both the basic controller topics and the combination controller made up are described in this section.

\section{Controller}

The first basic controller is the Fuzzy Logic Controller. The design of this controller follows the closed-loop system design. By referring to the closed-loop system, it can be seen that this system has two inputs and one output. The two inputs are Error and delta Error, while the output is PWM. For more details on the Fuzzy Controller's input membership function, it can be seen in Figs 3 - 4. The output membership function is shown in Fig 5 , and for Rule can be seen in Table 2.

Table 2: Fuzzy Rule

\begin{tabular}{|c|c|c|c|c|c|}
\hline $\mathrm{D} / \mathrm{dE}$ & NB & NS & Z & PS & PB \\
\hline NB & NB & NB & NS & NS & Z \\
\hline NS & NB & NS & NS & Z & PS \\
\hline Z & NS & NS & Z & PS & PS \\
\hline PS & NS & Z & PS & PS & PB \\
\hline PB & Z & PS & PS & PB & PB \\
\hline
\end{tabular}

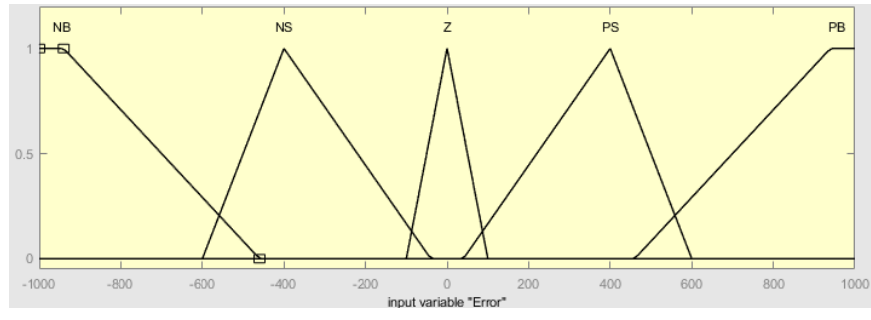

Figure 3: Membership of Error

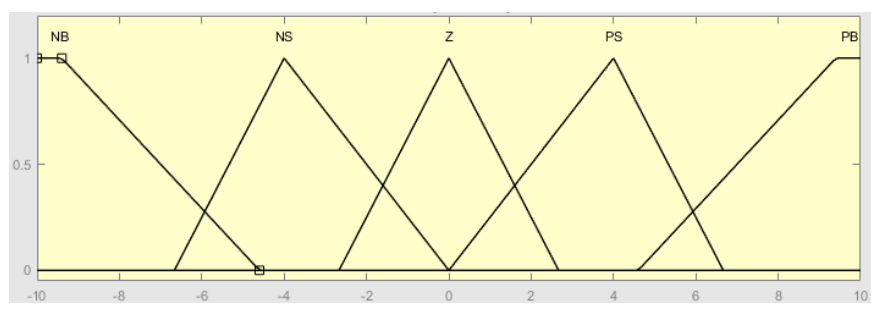

Figure 4: Membership of Delta Error

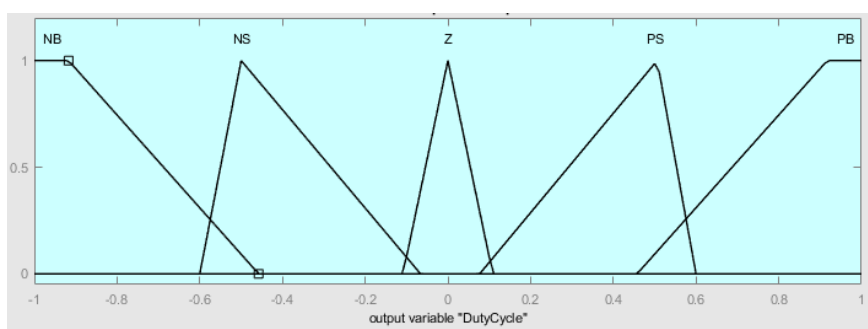

Figure 5: Membership of Output

Where $E$ is Error, $d E$ is delta Error, NB is Negative Big, NS is Negative Small, $Z$ is Zero, PS is Positive Small, PB is Positive Big.

The second controller is an Artificial Neural Network (ANN). The ANN architecture used consists of two inputs and one output. The layer used is a single hidden layer with ten neurons in it. Because ANN requires training data, the authors use training data created by researchers. The epoch used is 1000 epoch and produces a correlation or R-value of 0.99758 . The next control is PID control. In this PID control, the input used is different from other controllers. If the other controller inputs are Error and Delta Error, then on the PID control input, the input is Error only. Also, the PID control needs to be tuned so that the PID can work optimally. Thus, tuning the PID is done first using the Nichols - Zeigler tuning method. Then after the tuning process is complete, the ideal value is $\mathrm{Kp}=30, \mathrm{Ki}=750$, and $\mathrm{Kd}=0.3$.

\section{Controller Mechanism Setup}

For the block diagram of the BLDC motor speed control system, two blocks are used in this study. The first is a single closed-loop controller block, a control block for a single control system. The second is a closed-loop mode for a multi-controller block, a control block for control systems combined, or two combinations. All of the blocks work with closed-loop concepts where the error and delta error are the most important value to keep the system maintained according to the given setpoint. Before a deep discussion about the closed-loop controller 


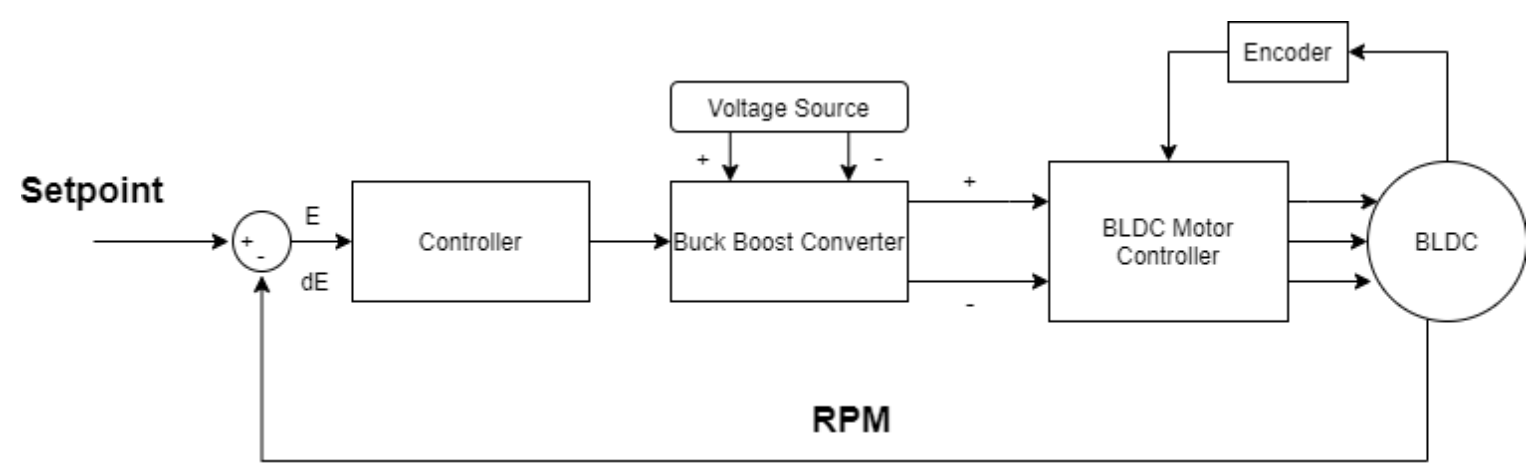

Figure 6: Single Controller Schematic

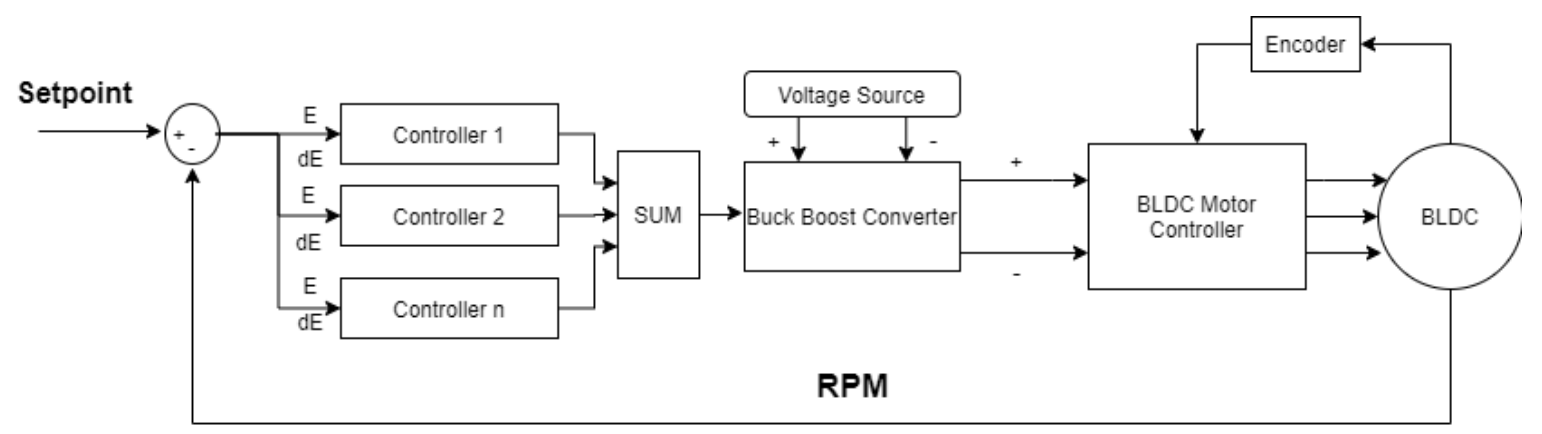

Figure 7: Multi-Controller Schematic (Proposed Tecnique)

discussed, the block diagram for each controller can be seen in Fig. 6 for a single control system and Fig. 7 for a multi-control system.

In general, the two blocks have almost similar performance and blocks. The first is input in the form of a setpoint. This input is a setpoint value, which is the speed desired by the user. At this input, the setpoint signal is not directly linked as controller input. But it will be reprocessed so that a closed-loop system is formed, which consists of only two inputs, namely Error and Delta Error. Therefore, the signal will be entered into the processing block, which will produce these two inputs. So that the block can be formulated with the following equation:

\section{$E=$ Ref-Feedback}

$d E=E_{(t-1)}-E_{o}$

Where $E=$ Error, the ref is the reference (setpoint), Feedback is the motor's output value, $\mathrm{dE}$ is Delta Error, $\mathrm{E}(\mathrm{t}-1)$ is the previous Error value, and $E_{0}$ is the current Error value. Because of the simulation used in Simulink Matlab, the equation is converted into Error and Delta Error blocks, which are then combined into a mux component before entering the black box control. But what needs to be paid attention to is that specifically for the PID Controller, the input used is only an error.

Furthermore, after passing through the signal processing block, the input signal processing outputs are fed to the controller. It is in this part that distinguishes between systems with single controllers and multi controllers. In a single controller, the input signal is directly linked to one controller, then the output from the controller in the form of a PWM signal will drive the Buck-Boost Controller directly. However, in a multi-controller, the signal processor's output signal will be linked to the combined controller simultaneously so that each controller gets Error and Delta Error values. If an output signal from the controller is directly linked to the Buck-Boost Controller on a single controller, the output signal will be processed first using the "SUM" block in multi controllers. The purpose of using this block is to combine the outputs of the installed controller to control one Buck-Boost Controller device with only one output, the combined PWM. Using this block, each controller installed will respond to the same changes to the input, which is the controller's response. Because the incoming change response is the same, the PWM will have a greater or lesser value because each controller contributes to changes in the existing input. Thus, the output from this multi-controller will correct each other. The resulting output tends to result from the improved response from each controller or output with combined characteristics of each controller working singly.

Furthermore, the control output (either single or multi-controller) is the PWM used to control the BuckBoost Converter. The function of the Buck-Boost Converter is to control the voltage that goes to the BLDC motor controller. The greater the input voltage, the faster the speed value produced by the BLDC motor.

\section{TESTING SCENARIO}

Testing this controller will be carried out by running a BLDC motor speed control by providing a speed setpoint: 500, 1000, 1500, 1000, 500, 3000, 500, 2000, 500. The setpoint is given to all controllers, either single controller mode and multi-controller mode. When the system runs, the author will record the data to know a system 
response representing the system with a setpoint and saves the system response output into the datalogger. The purpose of this storage is to measure the performance of each controller used using statistical parameters. These parameters include Integral Absolute Error (IAE), Integral Square of Error (ISE), Integral Time Absolute Error (ITAE), and Mean Absolute Error (MAE) [26, 27]. The equation of these statistical. From the equations previously, it can be known that the system requires several parameters to be able to generate values for each statistical parameter. Some of the statistical parameters include simulation time, setpoint, and BLDC motor speed output. Therefore the two data will be stored in the datalogger during the experiment.

The discussion in this study will focus on proving the contribution of multi controllers to a single controller. Therefore, the reference used is statistical parameters, which can be numerically analyzed easily compared to graphs. The discussion regarding the contribution from the multi-controller will be displayed in a contribution matrix. This matrix is a table that represents the amount of multi-controller improvement on a single controller in percent. The equations used in this matrix are:

Contribution $=\frac{(P V \text { Single Controller-PVMulti Controller })}{P V \text { Single Controller }} \times 100 \%$

Where $\mathrm{PV}$ is the Performance Value, with Eq.3, it can be concluded that if the value in the matrix is positive, this indicates that the system is contributing positively (an improvement in these parameters). Meanwhile, if the matrix is negative, its means that the system has a negative contribution (worse than the single controller).

\section{RESULT AND DISCUSSION}

After the setup process is formed, the next step is to test based on the previous section's scenario. Because of hard to analyze the system through the response system and the analysis process will be arduous, so in this study, to make it convenient, the assessment will be carried out using statistical parameters that are widely used to assess control system response. The result from the analysis of the statistical parameters can be seen in the chart in Figure 8.

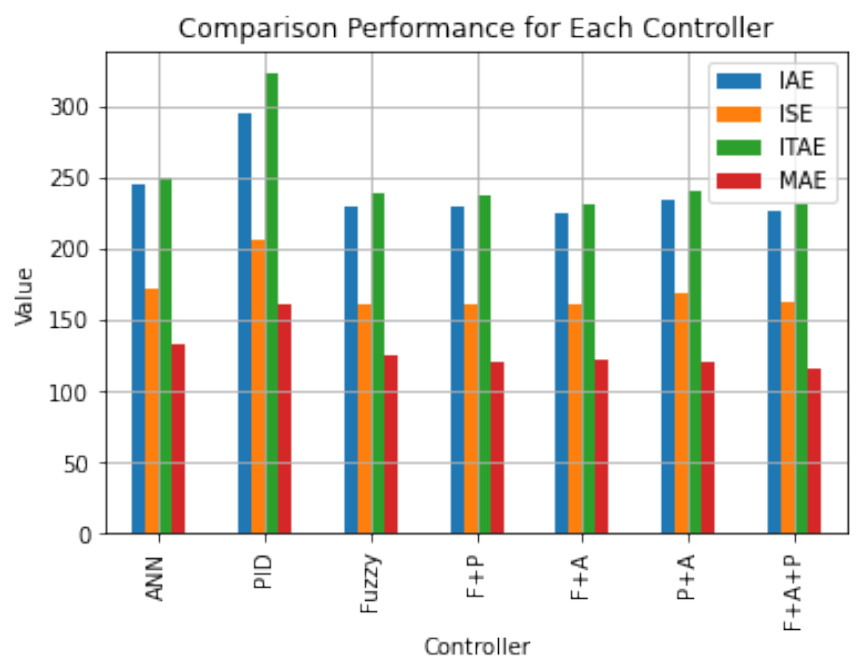

Figure 8: Comparison Performance for Each Controller
In the chart, some abbreviations represented the combinational controller used. $F+P$ is Fuzzy and PID, F+A is Fuzzy and ANN, P+A is PID and ANN, and the last $F+A+P$ is Fuzzy, ANN and PID. Fig. 8 discusses the graphical characteristics of each controller. It is known that each controller has different characteristics. Some of these characteristics, such as PID, which has a higher ITAE than others, or then Fuzzy, have a lower MAE than others. However, to know the improvement rate more clearly, the previous results need to be converted into a contribution matrix form. Multi-control might give a correct output's response from each controller combined in the multi-controller, so it reached the best value for each parameter. The correct value might increase the output value, so it could get the system response to be fast, or maybe decreasing to the response system, causing a higher response and might make the system getting worse. To analyze this point, it hard when it analyzes by using the responses system graph, cause the scenario in a continuous system. In addition, it will not know whether the point is an improvement or an error. This is because the system runs continuously, and the output is determined by summing the total response in a certain time. So to make it easy to interpret, the contribution matrix equation deploys to determine performance in a continuous system in the overall time response. Following the explanation in the previous section, this contribution matrix is a matrix that represents the value of the contribution given by multi controllers to controllers that work single. The equation used to calculate this can be seen in Eq. 3. Meanwhile. the results of each contribution can be seen in Figs 9 - 12.

From the table on the contribution of multi controllers to a single controller, multi controllers can make a positive contribution or contribute to improvements in several parameters in general. This is indicated by the number of positive values in each correlation parameter assessment, especially in MAE., where all the matrix values have positive values. This shows that the multi-controller has contributed to reducing the difference between the setpoint and the actual speed. However, the results show

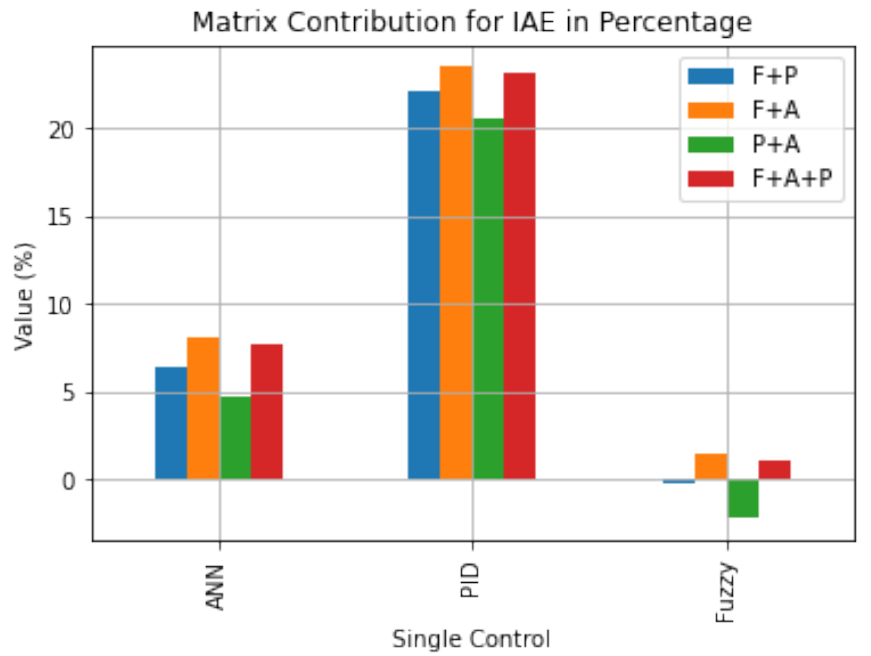

Figure 9: Contribution for IAE in Percentage Chart 


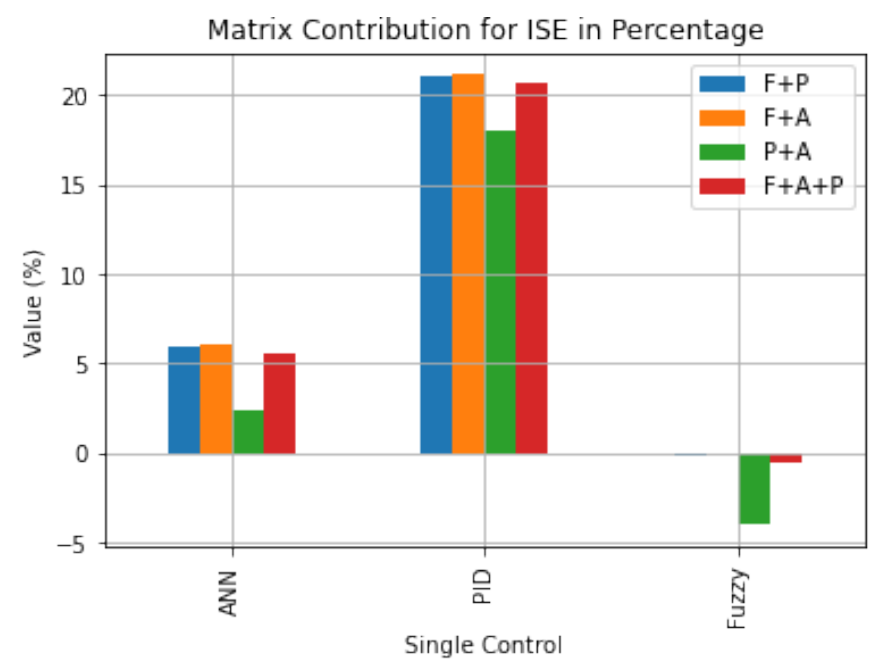

Table 10: Matrix Contribution for ISE in Percentage Chart

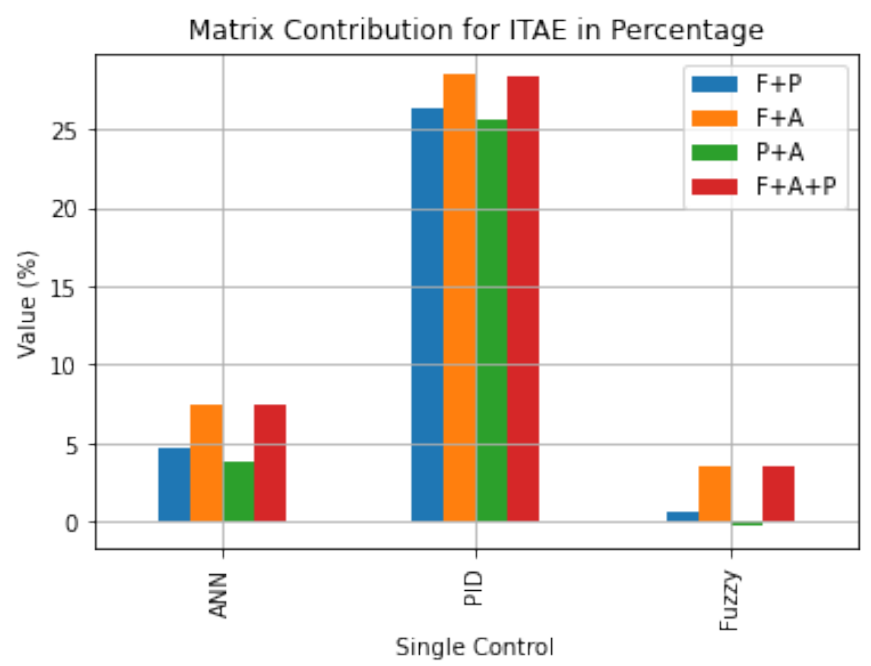

Figure 11: Matrix Contribution for ITAE in Percentage Chart

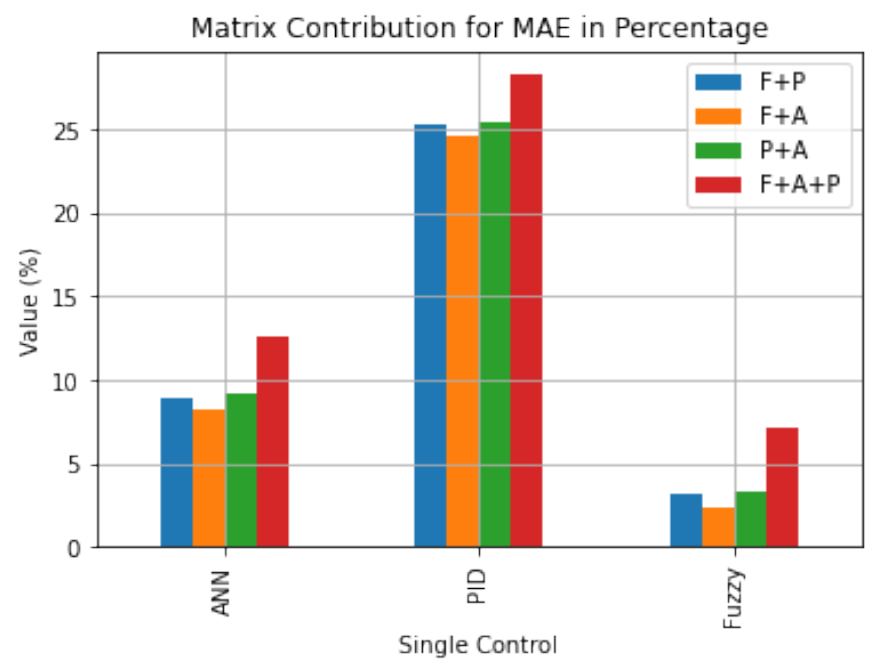

Figure 12: Matrix Contribution for MAE in Percentage Chart

that not all combined results positively contribute (indicated with positive value) to the system working as a single controller. One of them is the ISE parameter between
Fuzzy, PID, and ANN with Fuzzy Single Controller. In this parameter, the combination control negatively impacts -0.56 (negative value) on the ISE value. This means that the combined control has a side effect of generating a more significant oscillation value than the single control. This happens because, in the ISE parameter, the error value is squared, so that a large error will significantly impact the output value of this parameter. Besides, the ISE parameter also has a negative contribution between Fuzzy as Single Control and its combination control in Fuzzy PID and Fuzzy ANN.

Thus, it can be proven that combining controllers using the "SUM" method has contributed to improvements compared to the single controller. Although at some points, this combination controller has a negative impact.

\section{CONCLUSIONS}

In this research, a comparison test of BLDC motor speed control between a single controller and a multi-controller is combined with the summation concept. The test is carried out on seven controllers, combined controllers of the single and multi controllers. By doing dynamic testing, changing the setpoint value, several results were obtained and analyzed using statistical parameters. The results obtained indicate that the controller's combination using the summation concept has a positive contribution or improves BLDC motor speed control than if the system works as a single controller. The impact of this improvement occurs in the four statistical assessment parameters used in this study.

However, this research is still limited to combining it with the summation concept so that the output of the control is purely the result of combining controllers. Therefore, further research suggests that the output of the combination controller can be further controlled.

\section{REFERENCE}

1. 1. Joseph Godfrey, A., \& Sankaranarayanan, V. (2018). A new electric braking system with energy regeneration for a BLDC motor driven electric vehicle. Engineering Science and Technology, an International Journal, 21(4), 704-713. https://doi. org/10.1016/j.jestch.2018.05.003

2. 2. Anshory, I., Robandi, I., \& Ohki, M. (2019). System Indentification of BLDC Motor and Optimization Speed Control Using Artificial Intelligent. International Journal of Civil Engineering and Technology (IJCIET), 10(07), 1-13.

3. 3. Akhtar, M. A., \& Saha, S. (2018). dSPACE Based Motor Testing Platform for Characterization of BLDC Motor Performance Under Different Loading Conditions. 2018 8th IEEE India International Conference on Power Electronics (IICPE), 1-6. https:// doi.org/10.1109/IICPE.2018.8709566 
4. 4. Apatya, Y. B. A., Subiantoro, A., \& Yusivar, F. (2017). Design and Prototyping of 3-Phase BLDC Motor. 2017 15th International Conference on Quality in Research (QiR): International Symposium on Electrical and Computer Engineering, 209-214. https://doi.org/10.1109/QIR.2017.8168483

5. 5. Tutaj, A., Drabek, T., Dziwinski, T., Baranowski, J., \& Piatek, P. (2018). Unintended synchronisation between rotational speed and PWM frequency in a PM BLDC drive unit. 2018 23rd International Conference on Methods \& Models in Automation \& Robotics (MMAR), 959-964.

6. 6. Karthikeyan, B., Ragavan, D., Maheshwaran, M., \& Priya, R. B. (2018). Fuel Cell Fed BLDC Motor Drive. Journal of Science and Technology (JST), 3(3), 35-43.

7. 7. Poompavai, T., \& Kowsalya, M. (2019). Control and energy management strategies applied for solar photovoltaic and wind energy fed water pumping system : A review. Renewable and Sustainable Energy Reviews, 107, 108-122. https://doi.org/10.1016/j. rser.2019.02.023

8. 8. Venu, G., \& Kalyani, S. T. (2018). Design of FOPI Controller for Speed Control of BLDC Motor. International Journal of Pure and Applied Mathematics, 120(6), 645-662.

9. 9. Kumari, S., \& Verma, V. K. (2018). GA Based Design of Current Conveyor PID Controller for the Speed Control of BLDC Motor. International Conference on "Computational Intntelligence and Communication Technology" (CICT 2018) International Conference on "Computational Intelligence and Communication Technology," 1-3. https://doi. org/10.1109/CIACT.2018.8480149

10. 10. Zhang, S., \& Zhuan, X. (2019). Study on adaptive cruise control strategy for battery electric vehicle. Mathematical Problems in Engineering, 2019. https://doi.org/10.1155/2019/7971594

11. 11. Latif, A., Arfianto, A. Z., Widodo, H. A., Rahim, R., \& T.Helmy, E. (2020). Motor DC PID System Regulator for Mini Conveyor Drive Based-on Matlab. Journal of Robotics and Control (JRC), 1(6), 185190. https://doi.org/10.18196/jrc. 1636

12. 12. Ahmed, A. H., El, A., Kotb, S. B., Ali, A. M., \& Ahmed, A. H. (2018). Comparison between Fuzzy Logic and PI Control for the Speed of BLDC Motor. International Journal of Power Electronics and Drive System (IJPEDS), 9(3), 11591. https://doi. org/10.11591/ijpeds.v9.i3.pp1116-1123

13. 13. Zhang, D., \& Wang, J. (2019). Fuzzy PID Speed Control of BLDC Motor based on Model Design. Journal of Physics: Conference Series, 1303, 1-6. https://doi.org/10.1088/1742-6596/1303/1/012124
14. 14. Avian, C., Sujanarko, B., \& Kaloko, B. S. (2019). Response Improvement of BLDC Motor Speed using Extreme Learning Machine Controller. International Journal of Engineering Research And Management, 06(11), 1-7.

15. 15. Kavathe, R., Chandle, J. O., Patil, N., \& Kokare, M. (2018). ANFIS Based Speed Control of BLDC Motor with Bidirectional DC-DC Converter. International Journal of Research and Scientific Innovation (IJRSI), V(Vi), 153-158.

16. 16. Hassan, A. K., Elksasy, M. S., Saraya, M. S., \& Areed, F. F. (2018). Brushless DC Motor Speed Control using PID Controller, Fuzzy Controller, and Neuro-Fuzzy Controller. International Journal of Computer Applications, 180(30), 47-52. https://doi. org/10.5120/ijca2018916783

17. 17. Ch, L., \& Palakeerthi, R. (2015). BLDC Drive Control using Artificial Intelligence Technique. International Journal of Computer Applications, 118(4), 5-9. https://doi.org/10.5120/20731-3100

18. 18. Gobinath, S., \& Madheswaran, M. (2020). Deep perceptron neural network with fuzzy PID controller for speed control and stability analysis of BLDC motor. Soft Computing, 24(13), 10161-10180. https:// doi.org/10.1007/s00500-019-04532-z

19. 19. Krishna Veni, K. S., Senthil Kumar, N., \& Senthil Kumar, C. (2019). A comparative study of universal fuzzy logic and PI speed controllers for four switch BLDC motor drive. International Journal of Power Electronics, 10(1-2), 18-32. https://doi.org/10.1504/ IJPELEC.2019.096805

20. 20. Varshney, A., Gupta, D., \& Dwivedi, B. (2017). Speed response of brushless DC motor using fuzzy PID controller under varying load condition. Journal of Electrical Systems and Information Technology, 4(2), 310-321. https://doi.org/10.1016/j.jesit.2016.12.014

21. 21. Zhang, D., \& Wang, J. (2019). Fuzzy PID speed control of BLDC motor based on model design. Journal of Physics: Conference Series, 1303(1). https:// doi.org/10.1088/1742-6596/1303/1/012124

22. 22. Sheng, Y., Wang, X., Wang, L., \& Hou, P. (2017). Fuzzy-PID control system design of brushless DC motor based on vector control. Proceedings - 2017 Chinese Automation Congress, CAC 2017, 2017-Janua, 5583-5587. https://doi.org/10.1109/ CAC.2017.8243777

23. 23. Kristiyono, R., \& Wiyono, W. (2021). Autotuning Fuzzy PID Controller for Speed Control of BLDC Motor. Journal of Robotics and Control (JRC), 2(5). https://doi.org/10.18196/jrc.25114 
24. 24. Ghany, M. A. A., Shamsledin, M. A., \& Ghany, A. M. A. (2017). A Novel Fuzzy Self Tuning Technique of Single Neuron PID Controller for Brushless DC Motor. 2017 Nineteenth International Middle East Power Systems Conference (MEPCOM), 1453-1458. https://doi.org/10.1109/MEPCON.2017.8301374

25. 25. Ramya, A., Balaji, M., \& Kamaraj, V. (2019). Adaptive MF tuned fuzzy logic speed controller for BLDC motor drive using ANN and PSO technique. The Journal of Engineering, 2019(17), 3947-3950. https://doi.org/10.1049/joe.2018.8179
26. 26. Özdemir, M. T., \& Öztürk, D. (2017). Comparative performance analysis of optimal PID parameters tuning based on the optics inspired optimization methods for automatic generation control. Energies, 10(12). https://doi.org/10.3390/en10122134

27. 27. Marzaki, M. H., Tajjudin, M., Rahiman, M. H. F., \& Adnan, R. (2015). Performance of FOPI with error filter based on controllers performance criterion (ISE, IAE and ITAE). 2015 10th Asian Control Conference: Emerging Control Techniques for a Sustainable World, ASCC 2015, 5-10. https://doi.org/10.1109/ ASCC.2015.7244851 